\title{
O Ensino de Matemática em um Número Especial da Revista The New Era, 1934
}

\section{Mathematics Teaching in a Special Issue of The New Era Magazine, 1934}

\author{
Rafaela Silva Rabelo* \\ ORCID iD 0000-0002-7883-7914
}

\begin{abstract}
Resumo
Em 1934, a revista The New Era, uma das revistas oficiais da New Education Fellowship (NEF), publicou um número especial sobre o ensino de Matemática. A NEF foi uma organização de natureza internacional, fundada em 1921, no âmbito do movimento internacional da Educação Nova, e que agregava membros de diferentes países, inclusive nomes de educadores de grande prestígio. O presente artigo explora os temas sobre Educação Matemática veiculados no referido número, bem como o conteúdo das discussões no que diz respeito a abordagens teórico-metodológicas, identificando elementos recorrentes e eventuais divergências. Na análise são consideradas questões editoriais ao mesmo tempo em que se busca reconstituir as redes de trabalho dos autores que colaboraram no número analisado e o lugar que o discurso de autoridade ocupa. Entre as constatações, percebe-se a preocupação em incluir autores de circulação internacional e abordagens que estavam em voga, como os métodos Decroly e Montessori. A abrangência dos diferentes ramos da Matemática e dos níveis de ensino também deixa evidente o objetivo de propiciar uma visão ampla das tendências em Educação Matemática no número especial. Entre os aspectos mais recorrentes estão o recurso a situações reais no ensino de Matemática, o protagonismo do aluno, a relação entre conteúdo e idade ideal e o papel de destaque da psicologia aplicada à educação. Todavia, a forma como alguns desses aspectos é interpretada aponta para divergências. Finalizando, o artigo destaca a potencialidade de se explorar conexões com o Brasil, como o caso da professora Alda Lodi.
\end{abstract}

Palavras-chave: New Education Fellowship. História da Educação Matemática. Revistas pedagógicas.

\begin{abstract}
In 1934, the The New Era magazine, one of the official magazines of the New Education Fellowship (NEF), published a special issue on Mathematics teaching. The NEF was an international organization, founded in 1921 within the international movement of New Education, which aggregated members from different countries, including some renowned educators. The following article explores the themes about Mathematics Education addressed in the aforesaid issue, as well as the content of the discussions concerning theoretic-methodological approach, this way identifying recurring elements and eventual divergences. The analysis focus on the editorial aspects, the authors' networks, and the authority speech. Among the conclusions, it is possible to notice the concern in including authors internationally recognized and widely known approaches, such as the Decroly and Montessori methods. The different branches of Mathematics and school levels make evident that the editor wanted to provide an overview of Mathematics Education tendencies. The appeal to real experiences in Mathematics teaching, the prominence of the student, the connection between subject matter and mental age, and the central role of the psychology applied to education are among the recurring aspects. However, the way some of these aspects are interpreted points out the divergences. Finally, the article highlights the potentiality of exploring connections with Brazil, such as the case of Professor Alda Lodi.
\end{abstract}

Keywords: New Education Fellowship. History of Mathematics Education. Educational Journals.

\footnotetext{
* Doutora em Educação, FEUSP. Pós-doutoranda, FEUSP, São Paulo, SP, Brasil. Endereço para correspondência: Rua Butantan, 235, Caixa Postal 61528, Pinheiros, São Paulo, SP, Brasil, CEP: 05424-970. Email: rafaelasilvarabelo@hotmail.com.
} 


\section{Introdução}

Em 1934, a revista The New Era $(\mathrm{TNE})^{1}$ publicou um número temático sobre o ensino de Matemática. Em circulação desde 1920, ao todo, três artigos sobre o ensino de Matemática haviam figurado nas páginas da revista até então, sendo o último deles publicado em 1926. Apesar da Matemática ser citada dentro de discussões mais amplas sobre abordagens metodológicas e questões curriculares, principalmente na educação pré-escolar e no ensino primário, a quantidade de artigos específicos publicados até aquele momento mostra que não era um tema de destaque no periódico. Portanto, o número especial publicado em janeiro de 1934 estabelecia um marco nas pautas da TNE quanto ao que se considerava relevante nas discussões sobre o ensino de Matemática à luz das abordagens modernas.

Lançada em 1920, inicialmente com o título Education for the New Era, a partir de 1921 passou a se chamar The New Era, encurtando o título por orientação dos editores em Londres (ENSOR, 1920). Em 1921, passou a figurar como a revista oficial da recém-criada New Education Fellowship (NEF) ${ }^{2}$. A NEF foi um grupo de natureza internacional, criado no contexto do pós-guerra, que via na educação um meio de promover a paz e evitar conflitos no futuro. A Fellowship divulgava, por meio de suas revistas associadas, de seus congressos internacionais e regionais e de suas seções e grupos afiliados em outros países, as ideias e experiências desenvolvidas sob a alcunha de "Educação Nova" (BRASTER; ANDRES, 2018; VIDAL; RABELO, 2019).

Enquanto revista oficial da Fellowship, a TNE desempenhava um importante papel na circulação dos debates em nível internacional. Com a criação das revistas Pour l'Ere Nouvelle, editada por Adolphe Ferrière, e Das Werdende Zeitatter, por Elizabeth Rotten, ambas em 1922, a NEF passou a contar com três revistas oficiais ${ }^{3}$. As revistas suíça ${ }^{4}$ e alemã tinham a missão de divulgar as atividades da NEF nos países francófonos ${ }^{5}$ e germanófonos, mas não eram simples traduções da TNE, como esclarece Ensor no editorial em que divulga a criação das revistas (ENSOR, 1922). Apesar de alguns artigos em comum, cada revista tinha

\footnotetext{
${ }^{1}$ No âmbito da pesquisa à qual o presente artigo se refere, foram analisados os números da revista referentes ao período entre os anos 1920 e 1960 . A revista ainda está em circulação.

${ }^{2}$ Em francês, a New Education Fellowship era conhecida como Ligue Internationale pour l'Éducation Nouvelle.

${ }^{3}$ Ao longo dos anos, a NEF passou a incorporar como afiliadas revistas de outros países, geralmente vinculadas às seções criadas.

${ }^{4}$ Em 1925, a revista Pour l'Ere Nouvelle, que até então era editada em Genebra, passou a ser publicada na França, apesar de continuar com Ferrière como redator.

${ }^{5}$ Além dos países francófonos, a Pour l'Ere Nouvelle também circulava em países de língua latina, nos quais Ferrière foi designado como interlocutor da NEF.
} 
autonomia na sua organização e escolha dos conteúdos publicados.

O presente artigo tem como proposta explorar os temas sobre Educação Matemática veiculados no número temático de 1934, bem como o conteúdo das discussões no que diz respeito a abordagens teórico-metodológicas. Desta forma, pretendo identificar as pautas recorrentes na publicação e perscrutar as suas conexões com o movimento internacional da Educação Nova. Os resultados aqui apresentados são desdobramentos de pesquisas iniciadas em $2015^{6}$.

Além de ser um tema ainda não abordado, explorar a presença da Educação Matemática na revista TNE é relevante ao considerar a projeção internacional da NEF na divulgação de discussões e relatos de experiências educacionais sob a égide da Educação Nova. A TNE, enquanto fonte, permite identificar as diferentes apropriações da Educação Nova e, desta forma, as representações sobre o ensino de Matemática que conviviam no mesmo período, assim como a forma como essas percepções se alteram ao longo das décadas. Além disso, serve como parâmetro para estudos de cunho comparado ou sobre circulação e apropriação de ideias em diferentes países. Nesse sentido, oferece possibilidades de comparação com o que circulava no Brasil e de análise de possíveis conexões partindo da noção de circulação internacional de ideias/sujeitos/objetos.

Enquanto abordagem teórico-metodológica, exploro questões editoriais bem como as funções desempenhadas por impressos pedagógicos (CATANI, 1996; TOLEDO, CARVALHO, 2013). Ao explorar o número especial, a análise não se detém apenas na edição em si, mas também busca conexões com a NEF, reconstituindo as redes de trabalho dos autores que colaboraram no número analisado e examinando o recurso ao discurso de autoridade (CERTEAU, 2012; FUCHS, 2007).

Em um primeiro momento, caracterizo o número temático de 1934, descrevendo elementos editoriais da revista, enumerando os textos publicados, explorando o perfil dos respectivos autores e perscrutando as escolhas em termos de decisões editoriais e discurso de autoridade. Assim, inquiro sobre as razões para a publicação de um número sobre ensino de Matemática com base na própria trajetória da revista. Em um segundo momento, sintetizo o conteúdo dos artigos e detecto o escopo das discussões que compõem a edição temática.

\footnotetext{
${ }^{6} \mathrm{O}$ presente artigo articula resultados de dois projetos que investigam a New Education Fellowship e suas conexões com o Brasil. O primeiro, coordenado por Diana Vidal, intitulado "Educação transnacional: (des)conexões entre Brasil e a New Education Fellowship (1920-1948)" (Processo FAPESP 2015/06456-1). O segundo, pesquisa de pós-doutorado desenvolvida por Rafaela Rabelo, intitulada "Perscrutando o papel da Progressive Education Association na circulação da New Education Fellowship no Brasil (1920-1940)" (Processo FAPESP 2016/07024-0).
} 
Apesar de extensa, a segunda parte é fundamental na identificação de elementos-chave na parte seguinte. Em um terceiro momento, identifico a presença de temas que sejam recorrentes, convergências e divergências nas abordagens e nas concepções, relacionando com o que podem ser consideradas tendências internacionais sobre o ensino de Matemática nos anos 1930. Na sequência, sinalizo perspectivas em que a revista de Londres pode ser pensada em conexão com o Brasil, apresentando como exemplo o acervo da professora mineira Alda Lodi. Finalizo traçando um panorama geral do número temático analisado e apontando para desdobramentos em potencial.

\section{Caracterização do número especial sobre ensino de Matemática da The New Era}

O número temático sobre Matemática, em 1934, foi o primeiro do volume 15 , publicado em janeiro daquele ano. A iniciativa de publicar uma edição especial não era isolada e a revista já havia dedicado números a temas específicos anteriormente. Todavia, a publicação de edições especiais com editores convidados apenas havia começado no ano anterior. Primeiramente, em abril de 1933, a revista contou com a participação de F. C. Happold como editor convidado abordando a reconstrução do currículo. Em outubro de 1933, os editores da revista informavam em um curto parágrafo no cabeçalho do editorial que, a partir daquele número, a revista iniciava uma série de publicações com editores convidados, começando por Dimitry Katzaroff, que escreve a coluna-editorial ${ }^{7}$. A ele se seguiram Agnes Pirie, sobre a criança em idade pré-escolar, em novembro, e William Boyd, sobre a educação dos pais, em dezembro. O número temático sobre ensino de Matemática em janeiro do ano seguinte foi o último da série dos números com editores convidados.

Portanto, longe de ser um evento isolado, a edição especial sobre Matemática se inseria em uma série de publicações que seguia essa mesma linha. Todavia, não explica a escolha da Matemática como um dos temas. Antes da edição de 1934, o último artigo voltado à Matemática foi publicado em 1926, como mencionado anteriormente, escrito por Margaret Drummond (1926). Ao todo, foram publicados três textos sobre o ensino de Matemática entre 1920 e 1933, um número bastante reduzido ao considerar o início da circulação da revista e

\footnotetext{
${ }^{7}$ Ao contrário dos números seguintes, não é anunciado o tema de Katzaroff e ele não faz referências diretas aos artigos daquele número. A considerar o conteúdo dos artigos, o número do qual Katzaroff é editor convidado parece tratar de relatos de experiências desenvolvidas em escolas de diferentes países.
} 
sua periodicidade ${ }^{8}$.

Apenas é possível levantar algumas hipóteses para explicar a escolha da Matemática como parte da série de números temáticos com editores convidados que teve início em 1933. Desde o final do século XIX, os estudos sobre o ensino de Matemática vinham se multiplicando e ganhando mais espaço, no que Jeremy Kilpatrick (1996) e Miguel et al. (2004) consideram o início da constituição da Educação Matemática enquanto campo. Não por acaso, a Matemática estava entre as disciplinas que mais preocupavam os professores. Desta forma, a publicação da série de números especiais pela TNE pode ser interpretada como a oportunidade de abordar um tema que até então havia sido praticamente ignorado pela revista. É provável que os editores da revista tenham atendido a uma demanda direta de membros da NEF por mais espaço para se discutir o ensino de Matemática.

$\mathrm{O}$ editor escolhido para o número especial sobre ensino de matemática foi $\mathrm{P}$. $\mathrm{B}$. Ballard. O perfil apresentado pela revista ${ }^{9}$ traz algumas pistas do lugar de autoridade que ele ocupava. A revista informa que ele foi Divisional Inspector of Schools no London County Council (LCC), e que era o autor de Fundamental Arithmetic, Teaching the Essentials of Arithmetic e The New Examiner (THE NEW ERA, 1934, p. vi). Todavia, o curto perfil não dá toda a dimensão da atuação de Ballard, que conta com um verbete no Oxford Dictionary of National Biography.

Nascido em Glamorgan, Phillip Boswood Ballard (1865-1950) alternou sua formação e atuação docente entre o País de Gales e Londres. Pela University of London, graduou-se em 1891. Em 1903, concluiu o mestrado. Passou a atuar como inspetor escolar do LCC em 1906, quando começou a desenvolver interesse pela psicologia educacional. Com a publicação de Obliviscence and Reminiscence em 1913, foi contemplado com um doutorado honorário pela University of London. Ele foi um dos principais pioneiros da psicologia educacional moderna britânica, ao lado de nomes como W. H. Winch, Charles Spearman, John Adams, Thomas Percy Nunn e Cyril Burt. Ajudou a popularizar o trabalho sobre testes mentais de Burt, pelo qual foi influenciado, e foi responsável por introduzir a Psicologia no Departamento de Educação do LCC, onde aposentou-se em 1930, aos 65 anos (ROBINSON, 2004).

O que determinou a escolha do seu nome como editor de um número sobre ensino de Matemática? Há pelo menos dois aspectos a serem considerados que certamente pesaram na escolha. Primeiramente, sua atuação como inspetor do LCC. Mesmo que a revista fosse uma

\footnotetext{
${ }^{8}$ Inicialmente, a revista era trimestral. A partir de julho de 1930 passou a ser mensal, apesar de nem sempre completar doze números por ano.

${ }^{9}$ A revista trazia, no início de cada número, uma página com a apresentação dos autores colaboradores.
} 
publicação oficial da NEF, e que esta fosse uma organização de natureza internacional, é preciso considerar que a sede principal estava situada em Londres, onde a revista também era editada. A seção inglesa da NEF, fortemente vinculada ao Instituto de Educação de Londres por meio de vários de seus membros mais renomados - como Percy Nunn -, também estava em Londres. Portanto, parece natural que, ao considerar os editores convidados, os nomes mais próximos viessem à tona.

A questão geográfica e as redes de trabalho, todavia, não devem ser analisadas desconsiderando o prestígio e a autoridade atribuídos ao editor convidado. Ballard, além de cargos que certamente lhe possibilitaram ser reconhecido em terras britânicas, era uma referência internacional, principalmente por seus estudos sobre testes. Segundo Huerta (1951), um dos testes coletivos de inteligência mais difundidos nas primeiras décadas do século XX, em diversos países, foi por ele elaborado e ficou conhecido como test Ballard.

O número da TNE sobre o ensino de Matemática conta com um editorial e nove artigos, dos quais oito fazem parte do conjunto sobre ensino de Matemática que compõe a

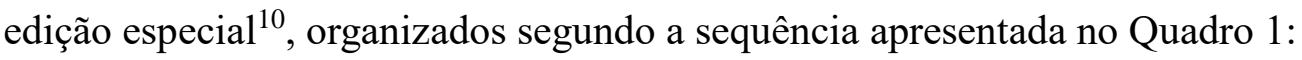

\begin{tabular}{|l|l|l|l|}
\hline Ord. & Autor & Título & Páginas \\
\hline- & P. B. Ballard & Outlook Tower & $1-3$ \\
\hline 01 & A. Hamaïde & Elementary Mathematics at the Decroly School & $3-8$ \\
\hline 02 & A. M. Maccheroni & Mathematics and the Montessori Method & $8-11$ \\
\hline 03 & M. Drummond & The Psychology and Teaching of Number & $12-16$ \\
\hline 04 & C. Washburne & Why is Arithmetic a Bugbear? & $17-23$ \\
\hline 05 & A. L. Atkin & The Teaching of Elementary Geometry & $23-27$ \\
\hline 06 & C. V. Durell & Algebra and General Education & $27-31$ \\
\hline 07 & R. H. Coombe & Living Mathematics and Sixth Forms & 32 \\
\hline 08 & E. R. Hamilton & Music and Mathematics & $33-36$ \\
\hline
\end{tabular}

Quadro 1 - Número especial sobre ensino de matemática na The New Era Fonte: The New Era (1934).

Ballard escreve o editorial do número especial, a seção fixa intitulada Outlook Tower. Não o classifico entre os artigos, pois, enquanto editorial, atende a um objetivo diferente, estabelecendo interlocução e emitindo percepções sobre os trabalhos que compõem o conjunto de textos sobre ensino de Matemática. Esses aspectos serão retomados ao longo da análise aqui empreendida. O editorial escrito por Ballard não explica os critérios para a escolha dos autores, mas é possível fazer algumas inferências. Parece razoável que os autores tenham escrito os textos atendendo a pedido do editor convidado, hipótese reforçada pelo fato de não haver referências ao número temático nas publicações anteriores.

\footnotetext{
${ }^{10} \mathrm{O}$ nono artigo, intitulado Freedom and Discipline in Education, de Margaret Lowenfeld, não faz parte do conjunto de textos sobre ensino de Matemática e, portanto, não foi incluído na análise. A segunda parte do referido artigo é publicada no número seguinte da revista.
} 
Na página que reune o perfil dos autores, é possível ter um vislumbre da forma como o número temático foi pensado e organizado com base na inserção profissional, publicações e expertise dos educadores ali reunidos. O espaço de uma única página destinado pela revista aos perfis certamente levou a omitir várias informações relevantes, o que busco contornar, também de forma resumida, na sequência, ao apresentar os autores na mesma ordem em que seus artigos aparecem na edição.

Amelie Hamaïde era:

Diretora e Professora de Pedagogia na Escola Decroly, l'Ecole de l'Ermitage, em Bruxelas, e um membro do Conselho Executivo da New Education Fellowship. Em colaboração com o recentemente falecido Dr. Decroly escreveu Le Calcul et la Mesure, e um de seus livros - La Methode Decroly - foi traduzido para o inglês (The Decroly Class) (THE NEW ERA, 1934, p. vi, tradução nossa).

Hamaïde foi uma importante colaboradora de Decroly e ocupou-se de divulgar o método por meio de artigos e em viagens internacionais. O livro La Methode Decroly foi um sucesso de vendas e contribuiu na disseminação e fixação do método (VAN GORP et al., 2017). Sua atuação na Ecole de l'Ermitage se deu entre 1911 e 1934. Em 1934, ela fundou sua própria escola, Ecole Nouvelle Amelie Hamaïde (DEPAEPE et al., 2003).

Anna Maccheroni foi "uma das primeiras professoras italianas a ser treinada pela Dra. Montessori. Ela foi Diretora de várias das famosas escolas Montessori e é ela quem mais colaborou com Dra. Montessori no aspecto musical do método" (THE NEW ERA, 1934, p. vi, tradução nossa). Semelhante a Hamaïde, Maccheroni também foi uma colaboradora e amiga de longa data de Montessori e uma divulgadora engajada de seu método ${ }^{11}$. Conforme revela Kramer (2017), Maccheroni acompanhava Montessori em várias de suas viagens e auxiliava nas conferências e nos experimentos nas escolas conduzidos em diversos países.

Margaret Drummond era professora de Educação na University of Edinburgh e vicepresidente da Nursery School Association. O seu perfil menciona os livros The Dawn of Mind, Five Years Old or Thereabouts e The Psychology and Teaching of Number (THE NEW ERA, 1934, p. vi). Também vale citar os livros Elements in Psychology - em coautoria com Sydney Herbert Mellone, Some Contributions to Child Psychology, e The Psychology of the PreSchool Child - em coautoria com James Drever - publicados em 1922, 1923 e 1929, respectivamente. Dentre os autores, Drummond é a única que já havia publicado um artigo

\footnotetext{
11 Ovide Decroly (1871-1932), educador belga, e Maria Montessori (1870-1950), educadora italiana, ganharam projeção internacional com os métodos de ensino que desenvolveram e ficaram conhecidos como métodos Decroly e Montessori. Em comum, ambos eram médicos que iniciaram seus estudos sobre aprendizagem com crianças com deficiência mental, posteriormente ampliando o foco (DEPAEPE et al., 2003; KRAMER, 2017; VAN GORP et al., 2017).
} 
especificamente sobre Matemática na TNE, como mencionado anteriormente. Também é a única que tem um de seus livros divulgados - The Psychology and Teaching of Number - no número temático.

Carleton Washburne era superintendente das escolas de Winnetka, Illinois, Estados Unidos. "Ele foi responsável por pesquisas extensivas sobre métodos individuais de ensino"12 e era "Presidente do Comitê dos Sete", que investigava "a idade ideal em que vários ramos da aritmética deveriam ser ensinados" (THE NEW ERA, 1934, p. vi, tradução nossa). É importante destacar que Washburne foi um membro atuante na Progressive Education Association (PEA), organização fundada nos Estados Unidos em 1919 e que, em 1932, se tornou a seção estadunidense da NEF. Era ligado à NEF desde os anos 1920, participando dos congressos internacionais e publicando nas revistas associadas. Entre 1939 e 1943, foi presidente da PEA e, entre 1949 e 1956, assumiu a presidência da NEF (WASHBURNE, 1971; RABELO, 2019; RABELO; VIDAL, 2019).

Sobre A. L. Atkin, a revista informa que tinha o título de Mestre pela Universidade de Oxford, e que anteriormente foi professor de Matemática na Christ's Hospital School (THE NEW ERA, 1934, p. vi). Não foram localizadas outras informações sobre o autor além das fornecidas pela revista.

Clement Durell era "bem conhecido entre os professores de matemática como o autor de numerosos livros didáticos [...] Ele conduziu alguns cursos de verão sobre o ensino de Matemática organizados pelo Conselho de Educação" e foi "professor sênior de matemática no Winchester College" (THE NEW ERA, 1934, p. vi, tradução nossa). Em 1932, publicou The Teaching of Elementary Algebra, que ganhou resenha bastante elogiosa de Ballard no mesmo ano (BALLARD, 1932). Segundo Price (1981), Durell se tornou um escritor bemsucedido de livros didáticos pela editora Bell e aponta para a influência de Percy Nunn em sua obra, especificamente em álgebra.

R. H. Coombe era professor de Matemática da Bishop Wordsworth's School, em Salisbury, e também mestre de coro responsável pelo "treino dos coristas da capela da escola" (THE NEW ERA, 1934, p. vi, tradução nossa). Assim como Atkin, também não foram localizadas informações sobre Coombe. É possível que tais autores não tenham investido em publicações ao longo da vida ou que supostas publicações não tenham tido a mesma projeção

$12 \mathrm{O}$ conjunto de experiências pedagógicas que Washburne desenvolveu em Winnetka ficou conhecido como Plano Winnetka, às vezes também referido como Sistema Winnetka. Um dos pontos de maior relevo do Plano estava relacionado às pesquisas sobre o ensino individualizado, que resultou na elaboração de manuais para o estudo individualizado dos alunos, com material de auto-correção e testes diagnósticos para medir o progresso Sobre as experiências em Winnetka, conferir Washburne e Marland (1963), Washburne (1971) e Graham (1971). 
que dos outros autores do número temático.

E. R. Hamilton era o diretor da Borough Road Training College, Isleworth e lecionava sobre a Psicologia da música e Matemática na University College, Bangor. É autor do livro The Art of Interrogation (THE NEW ERA, 1934, p. vi). O referido livro foi publicado em 1929 e contou com uma introdução de Charles Edward Spearman. No prefácio, Hamilton menciona Ballard nos agradecimentos por autorizar a citação de alguns de seus testes. No mesmo livro consta, nos elementos pós-textuais, uma lista de volumes da editora em preparação, entre eles The Psychology of Mathematics, de Hamilton. Não foram localizadas informações que confirmem que esse livro foi de fato publicado. Em 1935, publicou em coautoria com Ballard o livro Fundamental Geometry (BOON, 1935).

A organização dos artigos parece ter sido planejada em dois blocos. Um primeiro com autores de circulação internacional (Hamaïde, Maccheroni, Drummond e Washburne) e um segundo com autores britânicos (Atkin, Durell, Coombe e Hamilton). Apenas os autores do primeiro bloco contam com outras contribuições na revista anteriores à edição temática. Washburne é o autor com o maior número de contribuições na revista até $1933^{13}$, seguido por Drummond, Hamaïde e Maccheroni. Washburne e Drummond também contabilizavam várias publicações no formato de livros e de artigos em diferentes revistas por ocasião da publicação do número temático da TNE. Hamaïde e Maccheroni eram nomes principalmente vinculados à divulgação dos métodos Decroly e Montessori, respectivamente, educadores dos quais eram colaboradoras.

Ainda contrapondo os dois blocos de autores, no primeiro, todos eram membros atuantes da NEF. Além das colaborações na TNE, também publicaram na Pour l'Ere Nouvelle e/ou na Das Werdende Zeiteter, as outras revistas oficiais, e participaram dos congressos da NEF. Não foram localizadas informações que indiquem se os autores do segundo bloco também eram associados à NEF, o que é possível, já que a única condição era ser assinante de uma das revistas oficiais. É possível afirmar, ao menos, que faziam parte das mesmas redes que Ballard, fosse pelas vinculações ao LCC, ou simplesmente pelas publicações.

\section{Explorando os artigos do número temático}

O editorial escrito por Ballard estabelece previamente alguns protocolos de leitura (TOLEDO; CARVALHO, 2013), tais como o estatuto que o conjunto de artigos que compõem

\footnotetext{
${ }^{13}$ Incluindo todos os artigos, mesmo os que não tratam de Matemática.
} 
o número especial representam, os blocos temáticos em que os artigos podem ser agrupados, convergências e divergências. O texto tem início com um parágrafo traçando uma visão geral do lugar que aquele número especial ocupava:

\footnotetext{
Parece natural considerar a matemática - a matemática pura de qualquer forma como independente da mutabilidade que recai sobre várias das outras disciplinas escolares.

A sua antiguidade, seus conteúdos bem definidos, seu prestígio e suas tradições, todos tendem a estabilizar tanto o assunto quanto seu modo de tratamento. No entanto, aqueles que tiveram oportunidade de observar o ensino da matemática nas escolas nos últimos trinta anos podem testemunhar as mudanças não menos profundas que aquelas que ocorreram nas importações mais recentes para o programa escolar. Se outras evidências estavam faltando, os artigos nesta edição seriam prova suficiente. Trinta anos atrás eles possivelmente não poderiam ser escritos. Eles apontam não apenas para mudanças no passado, mas também para, provavelmente, ou de qualquer forma desejável, mudanças no futuro (BALLARD, 1934, p. 1, tradução nossa).
}

$\mathrm{Na}$ sequência, faz considerações sobre os primeiros anos de escolarização sob o subtítulo The Beginnings [Os Princípios], seguido pelos temas The Neglect of Geometry [A Negligência da Geometria], The Reform of Algebra [A Reforma da Álgebra], Music and Mathematics [Música e Matemática] e Premature Teaching [Ensino Prematuro], forma pela qual ele agrupa os assuntos discutidos nos artigos do número especial. Ao longo dos tópicos vai tecendo comentários gerais que, ao mesmo tempo que colocam em destaque elementos dos artigos e respectivos autores, também deixam transparecer suas próprias concepções. Retomarei alguns desses aspectos ao longo do texto.

$\mathrm{O}$ artigo de Amelie Hamaïde é apresentado logo após o editorial. Intitulado Elementary Mathematics at Decroly School [Matemática Elementar na Escola Decroly], trata da experiência de ensino de aritmética - com algumas referências à geometria - na École de l'Ermitage. Um dos pontos centrais no ensino de aritmética seguido na escola é a observação. É partindo dela que se desenvolve a prática de medir e comparar. Segundo esclarece Hamaïde, a observação à qual se refere não se resume à mera percepção, ao contrário:

[...] ela estabelece a relação entre os vários aspectos de qualquer objeto, entre amplitude e profundidade, luz e sombra. Também implica a consideração das relações temporais e espaciais e da realização de comparações, a análise de semelhanças e diferenças. Tal observação constrói uma ponte entre o mundo material e o mundo abstrato das ideias. Para tornar a observação mais precisa, a medição e o cálculo são obviamente necessários [...] (HAMAÏDE, 1934, p. 3, tradução nossa).

O interesse em Matemática, nessa perspectiva, seria despertado a partir da observação. As comparações - de vários objetos de diferentes naturezas -, inicialmente grosseiras, passariam a ser cada vez mais acuradas, transitando de qualidades não numéricas para numéricas, envolvendo quantidades contínuas e descontínuas. Termos quantitativos gerais 
seriam introduzidos paulatinamente, como "muito", "pouco", "mais", "menos", "suficiente", etc. O interesse também seria produzido a partir da observação de elementos do cotidiano, inclusive fazendo uso de materiais preparados com os alunos e coletados no dia a dia, a partir dos quais seria possível estimular o medir, o contar e o calcular.

Para a autora, antes que "as crianças sejam motivadas a usar as medidas abstratas convencionais adotadas por uma parcela da humanidade, é simplesmente racional dar-lhes oportunidades para usar unidades de medida naturais para quantidades descontínuas" (HAMAÏDE, 1934, p. 4, tradução nossa). As próprias crianças percebem, com a idade, que as medidas usadas são insuficientes e imprecisas. "Elas começam a descobrir por conta própria que as medidas que elas usam nem sempre são confiáveis" (HAMAÏDE, 1934, p. 4, tradução nossa).

Na sequência, é apresentado o artigo de Anna Maccheroni, que desenvolve seu texto focando o método Montessori, em artigo intitulado Mathematics and the Montessori Method [A Matemática e o Método Montessori]. Ela inicia pontuando que os "princípios do método Montessori são contundentemente ilustrados no ensino de aritmética e geometria" (MACCHERONI, 1934, p. 8, tradução nossa). Um dos pontos centrais do método é o incentivo das atividades espontâneas da criança. No caso da aritmética, Maccheroni observa que, geralmente, é tomado justamente o caminho contrário, ou seja, um ensino desnecessariamente formal.

[...] muitas pessoas tentaram torná-lo [o ensino de aritmética] interessante para crianças muito novas ao ensiná-la na forma de charadas. Eles administram para as mais velhas doses mínimas de uns poucos teoremas brevemente demonstrados, e um esquema de preparação para os exames organizado de forma que os estudantes estudem apenas o que é estritamente necessário. Demonstrações são dadas a mentes despreparadas para apreciá-las e em uma idade em que o interesse está ausente (MACCHERONI, 1934, p. 8, tradução nossa).

A abordagem escolhida por Maccheroni para explicar o método Montessori aplicado ao ensino de Matemática é a partir da descrição de exemplos de atividades envolvendo os materiais elaborados por Montessori. Ela menciona, por exemplo, o uso das barras (vermelhas e azuis), do material de contas (conhecido também como material dourado), dos encaixes geométricos, entre outros. As atividades em si, o manipular os materiais, despertam o interesse da criança, que atua como um explorador. A mente da criança procede para a abstração como resultado de um processo mental espontâneo. No método Montessori, a disposição mental da criança é respeitada (MACCHERONI, 1934).

Segundo Maccheroni, as crianças não ficam presas ao material montessoriano, o distanciamento ocorre espontaneamente. Essa observação não é casual, visto que um dos 
pontos de maior crítica ao método era sua dependência do material elaborado por Montessori, conforme pontua Kramer (2017). Portanto, antecipando as críticas, ou justificando as já existentes, Maccheroni defende que o método não se reduz ao material, que este compõe apenas uma fase.

Quanto à geometria na perspectiva do método Montessori, Maccheroni (1934, p. 10) destaca que a criança é capaz de reconhecer e nomear formas geométricas e observar diferenças na forma e no tamanho. Todavia, o objetivo não é a geometria em si, mas sim "educar o olho na observação das formas".

Além do material desenvolvido especificamente para a aplicação do método, Maccheroni menciona dois livros de Montessori sobre aritmética e geometria em fase de publicação. Apesar de não citar os títulos, trata-se certamente de Psico-geometria e Psicoaritmetica. Os livros foram publicados em 1934, originalmente em espanhol, pela Casa Editorial Araluce (MONTESSORI, 1934a; 1934b), um desdobramento do período que Montessori se fixou em Barcelona, inclusive fundando e conduzindo uma escola. Sua permanência na Espanha, o lar que adotou a partir de 1916, durou até 1936, quando a ditadura de Franco foi instaurada (KRAMER, 2017).

The Psychology and Teaching of Number [A Psicologia e Ensino do Número] é o título do artigo de Drummond, cujo cerne é a psicologia aplicada à educação. A potencialidade natural para o crescimento das crianças e como isso influencia na aprendizagem são os pontos centrais da discussão apresentada, em que a autora argumenta que o desenvolvimento deve ser levado em consideração. Nesse sentido, Drummond traça um paralelo sobre em que medida a aprendizagem está relacionada com o crescimento e quando o treino tem efeito. Afinal, o que é determinado pelo crescimento e o que é pelo treino? Para ilustrar o seu argumento, ela descreve um experimento com gêmeos por meio do treino individual de determinadas habilidades em diferentes períodos para determinar em que medida a maturidade influencia na aprendizagem.

Ela conclui que habilidades precisam de treino, o processo de crescimento por si só não é suficiente, mas o momento em que é feito também é determinante no resultado. Além disso, destaca que o treino é precedido pela compreensão. Nesse sentido, segundo Drummond (1934), o desenvolvimento do conceito de número também exige treino. Logo, o sucesso em aritmética nos Anos Finais não depende do tempo gasto nos Anos Iniciais, mas sim da combinação de crescimento, compreensão e treino.

Para Drummond (1934, p. 16), o interesse deve ser considerado na determinação do conteúdo. Também afirma que o interesse pelo número desperta por volta dos quatro anos e 
que, inicialmente, atividades como contar e nomear devem ser encorajadas, mas não corrigidas. Portanto, não deve haver trabalho formal sobre aritmética no primeiro ano escolar, o contar e o medir emergem naturalmente em atividades diárias. Erros na contagem não são importantes nessa fase. O recurso a jogos com números também é relevante. Além dos jogos, ela destaca que a aritmética "ensinada ao longo da escola elementar deveria ser determinada pelas necessidades e interesses da vida" (tradução nossa).

Após o artigo de Drummond, é inserido o texto de Carleton Washburne, intitulado Why is Arithmetic a Bugbear? [Por que a Aritmética é um Bicho-Papão?]. Nele, Washburne lista algumas razões para o fracasso escolar na disciplina e resultados de pesquisas por ele conduzidas. Segundo o autor, uma das principais razões para o fracasso das crianças na escola é a aritmética, apesar de ocupar a maior parte do horário e da tarefa de casa. Os alunos não fixam o que aprenderam e, a cada ano, os professores precisam revisar o que foi ensinado no ano anterior.

Entre as razões das dificuldades listadas por Washburne, estão os equívocos cometidos na seleção do conteúdo a ensinar; na organização do currículo; na preparação da criança; na motivação e na aplicação. Washburne (1934, p. 17) destaca também a confusão dos objetivos do ensino, visto que os professores adotam posturas que transitam por diferentes visões (disciplina formal; utilitarista; tradicionalista; vocacionalista), o que, ao fim "serve a nenhum de seus propósitos, pois tenta servir a muitos". O que importa é aquela "aritmética que com toda probabilidade será usada pela grande maioria das crianças. Este é o único critério legítimo para o currículo elementar de aritmética" (tradução nossa).

É preciso ajustar o currículo à criança, o que não ocorre na prática, visto que o programa de aritmética era organizado "logicamente, não psicologicamente. Apenas nos últimos anos algum esforço tem sido feito para descobrir a relativa dificuldade dos tópicos de aritmética e para descobrir o estágio do crescimento mental necessário para a aprendizagem efetiva de cada tópico" (WASHBURNE, 1934, p. 18, tradução nossa). Os estudos aos quais se refere foram conduzidos por um grupo que ficou conhecido como Comitê dos Sete, que se dedicou a explorar a organização do currículo de aritmética, testes de inteligência e testes sobre os fundamentos de aritmética. Os resultados do estudo apontaram uma idade mental ideal para aprender cada tópico em aritmética. A conclusão de Washburne (1934, p. 18) realça a necessidade de reorganizar o programa de aritmética, de acordo com o que as crianças estão psicologicamente preparadas, e que este seria "um dos meios mais efetivos para reduzir o fracasso em aritmética”.

Para além da idade, Washburne destaca outros elementos que devem ser observados no 
ensino de aritmética, como o fato que algum trabalho individual é necessário, visto que as crianças não atingem a maturidade mental ao mesmo tempo. Também aponta o recurso a situações reais e a atuação ativa dos alunos:

Os conceitos de número não são adequadamente desenvolvidos conversando. A
criança precisa ter experiência, quanto mais concreta e objetiva melhor, com as
realidades das quais os símbolos matemáticos são expressões. E ela deve ter ampla
prática em associar a realidade com o símbolo até que o símbolo instantaneamente e
infalivelmente evoque em sua mente um conceito da realidade [...] Coisas reais
manipuladas e situações reais quantitativamente satisfeitas: estas são as únicas bases
sólidas sobre as quais construir o ensino de aritmética (WASHBURNE, 1934, p. 20,
tradução nossa).

A motivação é outro aspecto enfatizado pelo autor. As crianças precisam entender o que e para que elas estão estudando aritmética, sendo o esforço empreendido proporcional ao interesse. Fazer com que as crianças tragam exemplos de casa ou de seu entorno pode ser muito útil, assim como apresentar situações baseadas na realidade para a classe ou trabalhar a partir de método de projetos.

Em seu artigo, The Teaching of Elementary Geometry [O Ensino da Geometria Elementar], Atkin não explicita o significado de “elementar". É possível que se refira à introdução do curso de geometria de acordo com o nível de ensino. Para Atkin, todos os iniciantes no estudo da geometria têm algum conhecimento prévio baseado no mundo ao seu redor, e que a função do professor é consolidar e desenvolver esse conhecimento. Uma das preocupações principais do autor é quanto à introdução do curso e a sequência dos conteúdos. Ele defende que a geometria formal apenas deve ser introduzida mais tarde.

Nas lições iniciais de geometria deve haver uma preparação abundante de trabalho prático e de exemplos práticos. $\mathrm{O}$ desenho que acompanha este trabalho exercita $\mathrm{o}$ aluno na descrição geométrica de objetos materiais e serve para familiarizá-lo com as abstrações geométricas de pontos, linhas, ângulos, etc., que entram nessa descrição: a esse respeito o ensino inicial de geometria apresenta um paralelo próximo ao ensino inicial de número (ATKIN, 1934, p. 23, tradução nossa).

Apesar de incentivar a introdução de exemplos e trabalhos práticos, sugerindo o recurso à construção e análise de modelos concretos, o autor alerta que devem ser situações que possam facilitar a abstração. Outro ponto é a importância do desenho no curso de geometria, com o uso de instrumentos, mas, principalmente, o incentivo ao desenho à mão livre. O desenho acurado deveria se restringir apenas a situações em que ele é imprescindível. "O aluno que aprende como fazer esboços à mão livre úteis e como lê-los e usá-los, adquire uma habilidade que é de grande valor ao longo do estudo da matemática, e posteriormente na vida" (ATKIN, 1934, p. 24, tradução nossa).

Dentre os artigos da revista, Atkin é o único que fala explicitamente sobre o recurso à indução e à dedução. Ele destaca a importância do método indutivo que, se corretamente 
empregado em um curso introdutório de geometria, pode acelerar o progresso e é relevante ao longo do estudo da Matemática. Nessa abordagem, fica a cargo do aluno analisar os dados e formular hipóteses. $\mathrm{O}$ autor salienta que a indução por si só não fornece prova matemática e, com o tempo, o aluno deve reconhecer suas limitações, o que introduziria naturalmente o raciocínio dedutivo.

$\mathrm{O}$ artigo seguinte, Algebra and General Education [Álgebra e Educação Geral], é escrito por Clement V. Durell. Em seu artigo, Durell ressalta que as reformas modernas no ensino da Matemática primeiro focaram a geometria e que as experiências dos últimos 30 anos levaram a um ponto que mostrava que articular o conteúdo com necessidades práticas e interesses era uma melhor abordagem. Quanto à álgebra, ele afirma que as mudanças foram mais recentes e que a tendência era "remodelar o curso introdutório por meio da introdução de fórmulas práticas do engenheiro, desta forma exemplificando a dependência de todo homem tecnicamente treinado do conhecimento matemático e da pesquisa" (DURELL, 1934, p. 27, tradução nossa). Buscando ultrapassar os processos abstratos com uma série de procedimentos sem sentido para os alunos, a tendência era que a aproximação da álgebra se desse a partir da "generalização de processos aritméticos e pela associação de tais generalizações com a vida cotidiana", por meio da invenção e interpretação de fórmulas (DURELL, 1934, p. 27, tradução nossa).

O autor menciona que a inserção de alguns exercícios é importante, mas que ainda ocorriam em excesso. Além disso, que o uso de problemas poderia ser tedioso ou estimulante e que são variados os exemplos que podem ser empregados, mas

[...] o melhor resultado apenas pode ser obtido por professores que estão preparados para se darem ao trabalho de produzir sua própria coleção de exemplos. Exemplos práticos de fórmulas e problemas fornecem critérios razoavelmente confiáveis de quais processos algébricos devem ser dominados que permitam o progresso nos ramos da matemática aplicada que os não-especialistas podem estudar proveitosamente (DURELL, 1934, p. 28, tradução nossa).

O uso de gráficos é outro elemento enfatizado pelo autor, argumentando que, apesar da fórmula ser "a mais abrangente e confiável”, o gráfico "fala mais vividamente". Além disso, abordar como aplicar o trabalho cotidiano da sala de aula no dia a dia também é relevante.

$\mathrm{Na}$ sequência, é apresentado o artigo Living Mathematics and Sixth Forms ${ }^{14}$ [Matemática Viva e os Anos Finais do Secundário], de Coombe. Um diferencial do artigo é a presença de um pequeno quadro contendo uma breve síntese do editor, no qual ele afirma que

\footnotetext{
${ }^{14} \mathrm{O}$ termo "Sixth forms" se refere aos Anos Finais do ensino secundário na Inglaterra, o equivalente aproximado ao Ensino Médio brasileiro, em que alunos com idade em torno de 16 a 18 anos se preparam para os exames de ingresso no Ensino Superior.
} 
“O Sr. Coombe descreve como um curso de matemática dos anos finais pode ser relacionado com o comércio e a indústria e desta forma servir como uma preparação valiosa para uma carreira em qualquer um deles" (BALLARD, 1934, p. 32, tradução nossa). Coombe inicia o artigo informando que os pais devem assinar um termo de compromisso que os filhos permanecerão na escola até os 16 anos, idade por volta da qual realizam exames para obtenção do School Certificate. Poucos permanecem na escola para tentarem o Higher Certificate e bolsas de estudo na universidade. $\mathrm{O}$ autor argumenta que é exatamente na fase após o School Certificate que se tem a melhor oportunidade de desenvolver certas aptidões com base na organização dos anos finais do secundário.

Ele sugere um curso de Matemática realista, trabalhado em conjunção com o curso de Economia. A justificativa seria que os alunos já teriam "uma boa base nos vários processos matemáticos, mas a ênfase principal tem sido atribuída à precisão e à habilidade de trabalhar exemplos específicos. No curso especial, é feita uma tentativa de relacionar a matemática com a vida" (COOMBE, 1934, p. 32, tradução nossa).

$\mathrm{Na}$ sequência, Coombe também sinaliza a adoção de debates a partir de resultados e levantamentos, permitindo aos alunos expressar suas opiniões e, ao mesmo tempo, ampliar a visão, o que seria muito útil no contexto em que viviam. Apenas quando todos os pontos fossem debatidos se recorria aos cálculos, de forma que "quando o trabalho com exemplos começar os garotos obtiveram tanta informação sobre o assunto que os exemplos se tornam matemática viva - a matemática que o mundo do comércio e da indústria está usando diariamente" (COOMBE, 1934, p. 32, tradução nossa).

O último artigo que compõe o número temático é o de E. R. Hamilton. Intitulado Music and Mathematics [Música e Matemática], Hamilton aborda os entrelaçamentos entre os dois campos, em uma reflexão teórico-filosófica. Ballard acrescenta um rápido comentário sobre o artigo em um quadro: "Música e matemática estão fundamentalmente relacionadas? Neste artigo o Sr. Hamilton discute a origem desta crença e analisa o prazer estético derivado da matemática, a mais abstrata das ciências, e da música, a mais abstrata das artes" (BALLARD, 1934, p. 33, tradução nossa). Por que Ballard insere comentários apenas nos últimos dois artigos? Podemos supor que ele quisesse dar maior visibilidade a Coombe e Hamilton, mas as razões são difíceis precisar.

É possível apreender concepções de Hamilton sobre o campo da Matemática, todavia, apenas na última meia página do texto ele faz qualquer conexão com a educação, levantando algumas questões em potencial. Ele questiona: "Podemos extrair qualquer moral pedagógica das relações conhecidas ou prováveis entre matemática e música?” (HAMILTON, 1934, p. 36, 
tradução nossa). Ele chega à conclusão que não havia estudos suficientes que mostrassem essa relação. Por um lado, ele critica as afirmações feitas por alguns músicos de que o estudo da música auxilia em outras atividades mentais, o que estaria relacionado com a doutrina das faculdades mentais, descartada pelos psicólogos. Por outro lado, ele acredita que não parece provável que o estudo da física dos sons levaria ao aumento da apreciação musical. Por último, ele aponta que os matemáticos têm um prazer estético específico de sua área, que pode ou não ser similar ao prazer da música.

Contrapondo música e Matemática, ele finaliza: “A apreciação da música significa, entre outras coisas, compartilhar alguns dos sentimentos do compositor; a apreciação da ciência significa, entre outras coisas, compartilhar alguns dos júbilos de um verdadeiro pesquisador" (HAMILTON, 1934, p. 36, tradução nossa). Estudar Matemática estaria amplamente relacionado com o ato de compartilhar as experiências dos "grandes aventureiros matemáticos", que, em grande medida, são de natureza estética.

\section{Comparando abordagens}

Mesmo tratando-se de um único número da revista, são vários os aspectos que poderiam ser explorados, tamanha a riqueza das informações e das conexões. Todavia, devido ao limite de páginas, restringirei a análise a algumas linhas mais gerais, como aquelas que remetem à metodologia e aspectos teóricos latentes na época.

O conjunto de artigos perpassam pelos diferentes ramos da Matemática (aritmética, geometria e álgebra) e níveis de ensino (pré-escolar, primário, secundário e algumas rápidas menções ao ingresso no ensino superior), o que demonstra a preocupação de organizar um número temático abrangente que fornecesse uma visão geral do ensino de Matemática na época. Em maior ou menor grau, todos os textos tratam de abordagens metodológicas e/ou organização curricular, com exceção do artigo de Hamilton, que tem como foco uma discussão teórica sobre o campo da Matemática e da música e, apenas ao final do texto, faz considerações sobre o ensino.

Dois dos artigos (Hamaïde e Maccheroni) desenvolvem a discussão com base em métodos de ensino específicos: método Decroly e método Montessori. Os referidos métodos não comparecem apenas no número especial sobre ensino de Matemática e tiveram destaque nas páginas da TNE desde que a revista começou a circular. Referências aos métodos e/ou atividades desenvolvidas por Decroly, Montessori ou seus discípulos são constantes nos editoriais da revista e nas seções de informações internacionais. O Plano Winnetka também é 
citado em diferentes números da TNE, mas não com o mesmo destaque que os métodos Decroly e Montessori. Esses fenômenos se repetem na revista Pour l'Ere Nouvelle.

O destaque dado aos métodos Decroly e Montessori nos números anteriores da TNE, bem como das outras revistas associadas, pode não ser a única explicação para a presença de artigos sobre os dois métodos no número especial. Como explicam Van Gorp et al. (2017), disputas entre os defensores de ambos métodos eram frequentes. Certamente, publicar um artigo sobre o método Decroly aplicado ao ensino de Matemática no número temático e não incluir um sobre o método Montessori, e vice-versa, seria alvo de críticas.

Apesar de não se deterem em um método de ensino específico, outros artigos do número especial especificam abordagens metodológicas e questões curriculares guiadas pela psicologia. A psicologia aplicada à educação é o cerne dos artigos de Drummond e Washburne e arbitra na decisão do que ensinar, com que idade ensinar e como medir a aprendizagem. Isso afeta, por exemplo, a introdução dos rudimentos de aritmética.

A idade para o ensino/aprendizagem da Matemática é um ponto recorrente, mesmo quando não abordado de forma explícita, e que deixa entrever divergências. Em Drummond e Washburne, a maturidade (idade mental) é o que determina o que ensinar, mas quando comparamos a idade apontada pelos autores há discrepâncias, por vezes significativas. Nesse sentido, Maccheroni aponta para a capacidade de as crianças aprenderem sobre número em uma idade muito anterior àquela indicada pelos outros autores. Esse aspecto ganhou a atenção de Ballard, que finaliza o editorial justamente enfatizando essa diferença entre os autores e demonstrando sua própria surpresa com os resultados apontados por Washburne.

De fato, os resultados apresentados pelo Dr. Washburne são tão surpreendentes em
suas implicações que não é possível se sentir confortável em sua própria mente até
que esses resultados sejam ou confirmados ou refutados neste lado das águas. Se
eles forem confirmados, então nosso programa de aritmética está totalmente
desacreditado - não em termos de conteúdo, mas de cronologia. [...] E se o Dr.
Washburne está certo, a Dr. ${ }^{\text {a }}$ Montessori está ainda mais visivelmente errada
(BALLARD, 1934, p. 3, tradução nossa).

A noção de interesse é uma das noções mais frequentes nos artigos, ganhando maior destaque e por vezes sendo associada diretamente à psicologia, ou sendo mencionada de passagem por meio de expressões como "interessante". Apesar de recorrente, o interesse é interpretado de formas diferentes quanto aos elementos que o despertam. Para Hamaïde, o interesse está diretamente relacionado com a observação, e a observação, por sua vez, com aspectos da realidade dos alunos. Concepções próximas à de Hamaïde são apresentadas por Drummond e Washburne. No caso de Washburne, ele deixa explícito que interpreta a noção de interesse a partir da psicologia, vinculada ao conceito de motivação. Uma percepção diferente 
é apresentada por Maccheroni, que relaciona o interesse à manipulação dos materiais montessorianos.

Outro aspecto recorrente é o recurso a situações reais, sejam elas da experiência dos próprios alunos (Hamaïde, Drummond, Washburne) ou aplicações a situações da vida como diferentes áreas de atuação profissional (Washburne, Durell, Coombe). A importância de tais situações "concretas" seria a de incentivar o aluno a ser autor de sua aprendizagem ao debater experiências, de muni-lo com conhecimentos úteis em sua atuação profissional futura ou como fator motivacional ao explicitar a importância da Matemática.

O papel do professor é apenas tangenciado nos artigos e nenhum deles se detém especificamente sobre a sua formação matemática. A atuação do professor aparece de forma mais explícita no texto de Washburne, no que diz respeito à organização curricular e no impacto que as concepções do professor têm no ensino de Matemática. As rápidas menções nos outros artigos colocam o professor na posição de facilitador, aquele que acompanha e intermedeia as atividades, que "conduz o aluno a" fazer alguma coisa. O aluno é o protagonista, ele debate, cita exemplos de seu dia a dia, propõe soluções, constrói ou coleta materiais que encontra no seu entorno para as atividades na escola.

O conjunto de artigos publicados no número especial sobre ensino de Matemática apresenta vários elementos relacionáveis com o movimento internacional da Educação Nova. Entre eles é possível salientar o papel crescente da psicologia aplicada à educação, arbitrando sobre a relação idade e organização curricular, motivação e interesse, avaliação da aprendizagem, dentre outros. O recurso a situações reais, seja com base nas experiências dos alunos ou a partir de aplicações da Matemática em diferentes áreas, também é recorrente, mas não é unanimidade. Nesse sentido, o número especial também revela diferenças nas abordagens e a heterogeneidade que o termo Educação Nova abrigava. Entre os artigos, por exemplo, o de Maccheroni é o que mais se distancia dos outros, tanto no que diz respeito à introdução do conceito de número, quanto à ausência da conexão com o dia a dia da criança, cabendo ao material montessoriano o papel de desencadear a aprendizagem.

É importante destacar que não é possível julgar as abordagens apresentadas e as próprias concepções dos autores com base unicamente nos artigos publicados no número temático. Para tanto, seria preciso investir em suas trajetórias profissionais e analisar outras publicações. Todavia, ao analisar esse conjunto de artigos publicado no início de 1934, colocando-os lado a lado, é possível vislumbrar alguns pontos centrais bem como convergências/divergências no que diz respeito ao ensino de Matemática. 


\section{Problematizando conexões com o Brasil}

A análise de uma edição temática sobre o ensino de Matemática, publicada por uma revista em Londres, em 1934, não é aleatória e pode ser pensada em conexão com o Brasil. Conforme sinalizado por Carvalho (2004) e em estudos recentes desenvolvidos por Diana Vidal e Rafaela Rabelo, é possível reconstituir redes que conectam educadores brasileiros e a NEF. Carvalho (2004) explora o impacto da NEF na elaboração do Manifesto dos Pioneiros da Educação Nova, de 1932. Já Rabelo e Vidal (2019) perscrutam a criação da seção brasileira da NEF em 1942, reconstituindo as redes que ligam educadores brasileiros com a Fellowship desde os anos 1920. Nesse cenário emergem nomes como Carneiro Leão, Laura Lacombe, Lourenço Filho, Noemy Rudolfer, Everardo Backheuser, entre outros. As autoras também identificam a atuação da Associação Brasileira de Educação (ABE) na constituição dessas redes.

No que diz respeito especificamente à Educação Matemática, sem a intenção de aprofundar a discussão, mas apenas apontar conexões com a NEF com potencial de investigação, é possível remeter ao acervo da professora mineira Alda Lodi. Em 1927, Alda fez parte de um grupo de professoras enviadas pelo governo de Minas Gerais para estudar no Teachers College, da Universidade de Columbia, em Nova Iorque. Durante o período que lá esteve, ela se dedicou ao estudo da metodologia do ensino de Matemática, retornando a Belo Horizonte em 1929, quando passou a atuar na Escola de Aperfeiçoamento recém-criada pelo governo mineiro. A viagem e estudos realizados por Alda em Nova Iorque são tema da dissertação de mestrado de Fonseca (2010). A esse estudo se seguiram outros focando especificamente a Educação Matemática com base no acervo da professora, entre eles os trabalhos de Reis (2014), Rabelo (2016) e Amorim (2018). O acervo de Alda, contemplado nos referidos trabalhos, evidencia a preocupação que a professora tinha em se manter atualizada com os estudos internacionais sobre o ensino de Matemática por meio da aquisição de publicações de autores reconhecidos.

No trabalho de Reis (2014), que traz um inventário de livros sobre Matemática que compõem a biblioteca pessoal de Alda Lodi, podemos vislumbrar vestígios das tendências em ensino de Matemática na época. Integrando o acervo está uma coleção de aritméticas de Washburne, publicada em 1927, e os dois manuais de Montessori (Psico-geometria e Psicoaritmética) publicados em espanhol, em 1934. Apesar de não constar no inventário de Reis 
(2014), também faz parte do acervo o livro The Psychology and Teaching of Number, de Drummond $^{15}$. Decroly e Hamaïde aparecem na bibliografia de livros que compõem a biblioteca, bem como em documentos do acervo, como cadernos e relatórios, segundo análise de Reis (2014). Todos esses autores fazem parte do bloco internacional do número temático da TNE analisado no presente artigo, escrevendo ou tendo seus métodos discutidos.

É possível que o grupo mineiro tenha tomado conhecimento da NEF durante a estadia no Teachers College. A chegada da Missão Europeia ${ }^{16}$, em 1929, por ocasião da criação da Escola de Aperfeiçoamento, em Belo Horizonte, e as interlocuções com o Instituto Jean Jacques Rousseau e o Bureau International d'Éducation são outras possibilidades, como sinalizado por Vidal e Rabelo (2019) e Rabelo e Vidal (2019). Mesmo que Alda não tivesse conhecimento da existência da NEF, ou da revista TNE, todas essas evidências nos levam a inquirir, no mínimo, como as redes constituídas pela NEF, que agregava educadores de vários países, se manifestavam no Brasil, especificamente no que diz respeito à Educação Matemática. Os vestígios estão presentes no acervo de Alda Lodi, mas também em programas de ensino, revistas pedagógicas e nos acervos de outros professores de diferentes regiões do Brasil e oferecem novas possibilidades de pesquisa no que diz respeito à Educação Matemática brasileira no âmbito do movimento internacional da Educação Nova.

\section{Algumas considerações}

Como apontado no começo deste artigo, a revista TNE, sendo uma publicação oficial da NEF, cumpria a missão de divulgar as atividades da associação e de grupos afiliados, assim como dar visibilidade a propostas e experiências pedagógicas inovadoras em âmbito internacional. Nesse sentido, a revista abria espaço tanto para nomes consagrados internacionalmente, quanto para o relato de experiências desenvolvidas por professores que não estavam inseridos no circuito acadêmico.

É possível inquirir sobre a TNE em pelo menos duas perspectivas e suas implicações especificamente na Educação Matemática. Primeiro, sobre o papel que cumpria na divulgação de propostas entre pesquisadores, professores, pais e entusiastas da educação, determinando

\footnotetext{
${ }^{15}$ Identifiquei a presença do livro de Drummond na biblioteca de Alda Lodi durante consulta ao acervo realizada em 2015. Conforme explico em Rabelo (2016, p. 131 e 146), durante a consulta ao acervo localizei alguns títulos que Reis (2014) não havia encontrado, assim como não localizei alguns examplares que o autor inclui em seu inventário, resultado, provavelmente, das mudanças de prédio pelas quais o acervo passou.

${ }^{16}$ Compunham a Missão Europeia Theodore Simon, Leon Walther, Artus Perrelet e Omer Buyse. Helena Antipoff se juntou ao grupo depois, substituindo Leon Walther (FONSECA, 2010).
} 
agendas e mesmo impactando nas práticas docentes. Segundo, tomando-a como fonte, sobre como a revista, independentemente de ter circulado em determinados espaços ou não, desvela temas que ocupavam a pauta internacional e diferentes concepções que conviviam sob a mesma alcunha de "Educação Nova". Este último caso pode ser pensado em consonância com a trajetória profissional de diferentes educadores, como o caso de Alda Lodi.

Do número temático de 1934, podemos apreender algumas tendências em curso, como a interlocução cada vez maior com a psicologia. Também há a preocupação com a organização do currículo adequando à idade e/ou ao interesse dos alunos. Esses elementos se fazem presentes principalmente no primeiro bloco de artigos, que trazem abordagens metodológicas que tiveram grande circulação, como os métodos Decroly e Montessori. Se no primeiro bloco, o foco recai nos primeiros anos de escolarização (educação infantil e/ou ensino primário), o segundo tende para o ensino secundário e seus desdobramentos (ensino profissional ou ingresso no ensino superior).

O número especial sobre ensino de Matemática de 1934 evidencia que o repertório em torno do tema era amplo e relevante o suficiente para ganhar uma edição temática, no entanto, a revista apenas voltou a publicar um artigo sobre o assunto em 1938. Para além dos artigos esporádicos, um longo hiato se seguiu até a Matemática ganhar um novo número temático, em 1959, sobre a introdução ao conceito de número e, em 1964, sobre a Matemática Moderna, o que leva a uma série de novas questões.

\section{Agradecimentos}

A autora agradece o apoio da Fundação de Amparo à Pesquisa do Estado de São Paulo (FAPESP), Processo no 2016/07024-0.

\section{Referências}

AMORIM, B. D. Indicações metodológicas para o ensino da Matemática presentes em livros que circularam em Minas Gerais na primeira metade do século XX: um estudo da biblioteca pessoal da professora Alda Lodi. 2018. 136 f. Dissertação (Mestrado em Educação) - Universidade Federal de Minas Gerais, Belo Horizonte, 2018.

ATKIN, A. L. The teaching of elementary geometry. The New Era, Londres, v. 15, n. 1, p. 23-27, jan. 1934.

BALLARD, P. B. Outlook tower. The New Era, Londres, v. 15, n. 1, p. 1-3, jan. 1934.

BALLARD, P. B. Teaching of mathematics. Nature, Londres, v. 129, n. 3264, p. 742-743, mai. 1932.

BOON, F. C. Fundamental Geometry by P. B. Ballard and E. R. Hamilton. The Mathematical 
Gazette, Leicester, v. 19, n. 235, p. 317-318, out. 1935.

BRASTER, S.; ANDRES, M. M. P. La escuela nueva en imágenes: fotografía y propaganda en The New Era (1920-1939). Historia y Memoria de la Educación, Madrid, v. 8, p. 97-145, 2018.

CARVALHO, M. M. C. O Manifesto e a Liga Internacional pela Educação Nova. In: XAVIER, M. C. (Org.). Manifesto dos pioneiros da educação: um legado educacional em debate. Rio de Janeiro: Editora FGV, 2004. p. 147-181.

CATANI, D. B. A imprensa periódica educacional: as revistas de ensino e o estudo do campo educacional. Educação e Filosofia, Uberlândia, v. 10, n. 20, p. 115-130, jul./dez. 1996.

CERTEAU, M. História e psicanálise: entre ciência e ficção. 2. ed. Belo Horizonte: Autêntica, 2012. COOMBE, R. H. Living mathematics and living forms. The New Era, Londres, v. 15, n. 1, p. 32, jan. 1934.

DEPAEPE, M.; SIMON, F.; VAN GORP, A. The Canonization of Ovide Decroly as a "Saint" of the New Education. History of Education Quarterly, Cambridge, v. 43, n. 2, p. 224-249, 2003.

DRUMMOND, M. Number for infants. The New Era, Londres, v. 7, n. 28, p. 153-157, 1926.

DRUMMOND, M. The psychology and teaching of number. The New Era, Londres, v. 15, n. 1, p. 1216, jan. 1934.

DURELL, C. V. Algebra and general education. The New Era, Londres, v. 15, n. 1, p. 27-31, jan. 1934.

ENSOR, B. The Outlook Tower. The New Era, Londres, v. 1, n. 4, p. 94, out. 1920.

ENSOR, B. The Outlook Tower. The New Era, Londres, v. 3, n. 9, p. 1, jan. 1922.

FONSECA, N. M. L. Alda Lodi, entre Belo Horizonte e Nova Iorque: um estudo sobre formação e atuação docentes 1912-1932. 2010. 159 f. Dissertação (Mestrado em Educação) - Universidade Federal de Minas Gerais, Belo Horizonte, 2010.

FUCHS, E. Networks and the History of Education, Paedagogica Historica, v. 43, n. 2, p. 185-197, 2007.

GRAHAM, P. A. Carleton Wolsey Washburne: a biographical essay. Teachers College Record, Nova Iorque, v. 72, n. 6, p. 487-494, 1971.

HAMAÏDE, A. Elementary mathematics at the Decroly School. The New Era, Londres, v. 15, n. 1, p. 3-8, jan. 1934.

HAMILTON, E. R. Music and mathematics. The New Era, Londres, v. 15, n. 1, p. 33-36, jan. 1934.

HUERTA, J. F. Estudio de la aplicación del test Ballard de inteligência en la escuela primaria. Revista Española de Pedagogia, Madrid, v. 9, n. 35, p. 391-406, 1951.

KILPATRICK, J. Fincando estacas: uma tentativa de demarcar a educação matemática como campo profissional e científico. Zetetiké, Campinas, v. 4, n. 5, p. 99-120, jan./jun. 1996.

KRAMER, R. Maria Montessori: a biography. Nova Iorque: Diversion Books, 2017. MACCHERONI, A. M. Mathematics and the Montessori method. The New Era, Londres, v. 15, n. 1, p. 8-11, jan. 1934. 
MIGUEL, A. et al. A educação matemática: breve histórico, ações implementadas e questões sobre sua disciplinarização. Revista Brasileira de Educação. n. 27, p. 70-93, set./dez. 2004.

MONTESSORI, M. Psico-aritmética: la aritmética desarrollada con arreglo a las directrices señaladas por la psicología infantil, durante veinticinco años de experiencia. Barcelona: Casa Editorial Araluce, 1934a.

MONTESSORI, M. Psico-geometria: el estudio de la geometría basado en la psicología infantil. Barcelona: Casa Editorial Araluce, 1934b.

PRICE, M. H. The reform of English mathematical education in the late nineteenth and early twentieth centuries. 1981. 405 f. Tese (Doutorado em Educação) - University of Leicester, Leicester, 1981.

RABELO, R. S. Carleton Washburne e o Departamento de Estados dos EUA: a educação latinoamericana em meio à política de boa vizinhança. In: Congresso Pensamento e Pesquisa sobre a América Latina, I, 2019, São Paulo. Anais... São Paulo: Prolam-USP, 2019.

RABELO, R. S. Destinos e trajetos: Edward Lee Thorndike e John Dewey na formação matemática do professor primário no Brasil (1920-1960). 2016. 286f. Tese (Doutorado em Educação) Universidade de São Paulo, São Paulo, 2016.

RABELO, R. S.; VIDAL, D. G. A seção brasileira da New Education Fellowship: (des)encontros e (des)conexões. In: VIDAL, D. G.; RABELO, R. S. (Org.). Movimento internacional da Educação Nova. Minas Gerais: Fino Traço, 2019, no prelo.

REIS, D. A. F. História da formação de professores de matemática do ensino primário em Minas Gerais: estudos a partir do acervo de Alda Lodi (1927 a 1950). 2014. 258 f. Tese (Doutorado em Educação) - Universidade Federal de Minas Gerais, Belo Horizonte, 2014.

ROBINSON, W. Ballard. Oxford Dictionary of National Biography. Oxford: University Press, 2004.

THE NEW ERA. Londres, v. 15, n. 1, jan. 1934.

TOLEDO, M. R. A.; CARVALHO, M. M. C. A tradução de John Dewey publicada na coleção Biblioteca de Educação. In: CONGRESSO BRASILEIRO DE HISTÓRIA DA EDUCAÇÃO, 7 ., 2013, Cuiabá. Anais... Cuiabá: SBHE, 2013.

VAN GORP, A.; SIMON, F.; DEPAEPE, M. Frictions and fractions in the New Education Fellowship, 1920s-1930s: Montessori(ans) v. Decroly(ans). History of Education \& Children's Literature, Macerata, v. 12, n. 1, p. 251-270, 2017.

VIDAL, D. G.; RABELO, R. S. A criação de Institutos de Educação no Brasil como parte de uma história conectada da formação de professores. Cadernos de História da Educação, Uberlândia, v. 18, n. 1, 2019.

WASHBURNE, C. W. An autobiographical sketch. Teachers College Record, Nova Iorque, v. 72, n. 6, p. 457-494, 1971.

WASHBURNE, C. Why is arithmetic a bugbear? The New Era, Londres, v. 15, n. 1, jan. 1934. WASHBURNE, C. W.; MARLAND, S. P. Winnetka: the history and significance of an educational experiment. Englewood Cliffs: Prentice-Hall, 1963. 